\title{
Managing Conflict of Interests in Professional Accounting Firms: A Research Synthesis
}

\begin{abstract}
This paper synthesises the research related to managing conflict of interests in professional accounting firms. The main purpose is to provide information about the current state of knowledge on this topic and to highlight the areas requiring further research. The extant research has been reviewed by developing a framework through the integration of Risk Management Framework by ISO 31000:2009 and the International Code of Ethics for Professional Accountants. Specifically, literature has been classified across the establishment of context, assessment, treatment, control and monitoring of conflict of interests. The literature reveals that there is a lack of understanding about how the conflict of interests operates at the level of an individual accounting professional. Addressing this gap will help to develop behavioural interventions for strengthening the professionals' independence in fact and, thereby, facilitating the management of conflict of interests.
\end{abstract}

The key message this synthesised research provides for professional accounting firms and the regulators is that, for effective management of conflict of interests, behavioural interventions should be informed by the professionals' unconscious (automatic) as well as their conscious (controlled) cognitive processes. This study is the first one to view the conflict of interests in a professional accounting environment through the lens of behavioural risk management. Moreover, the framework adopted for reviewing the extant literature provides a comprehensive view of the issues surrounding the ineffective management of the conflict of interests.

Keywords: conflict of interests, professional accounting, ethical decision-making, independence in fact, behavioural interventions, behavioural risk management. 


\section{Introduction}

This paper is meant to synthesise the research around managing conflict of interests in professional accounting firms. This is important to add to our understanding of why despite increased regulations, the problem of accounting professionals' deviant behaviour due to conflict of interests is still largely pervasive. Almost every year, the professional accounting firms face heavy fines on account of the deteriorated audit quality due to conflict of interests (Agnew 2015; Crump 2015; Withers 2018). Extant research reveals that this problem is largely pervasive due to ineffective management of conflict of interests (Bazerman and Gino 2012; Clements et al. 2012). Although the devastating effects of conflict of interests in professional accounting environment are welldocumented (see, for example, Boyd 2004; Daugherty et al. 2012; Favere-Marchesi and Emby 2005; Pierce and Sweeney 2004), research pertaining to managing conflict of interests is scattered across various topics. To be able to identify the current state of knowledge, there is a need to synthesise research - this stance has also been supported by recent research (see Endenich and Trapp 2018).

Specifically, literature relevant to managing conflict of interests is found in conjunction with research that pertains to the independence of professionals and the accounting firms' quality control procedures. There is convincing evidence in the literature that conflict of interests should be treated as a risk (see, for example, IESBA 2018; Johnson and Hansen 2011; Thagard 2007). Florio (2012) and Lo and Field (2009) considered the conflict of interests a risk and highlighted the need for identifying, assessing, controlling and monitoring the conflict of interests. Similarly, Bedard et al. (2008) also support the identification, assessment and control of conflict of interests. In this regard, various researchers (see, for example, Guiral et al 2010; Moore et al 2010) strongly 
support the adoption of behavioural perspective. Therefore, this study looks at the conflict of interests through the lens of behavioural risk management and defines conflict of interests as;

' a situation involving a disagreement between the accounting profession's primary interest and the professional's secondary interest(s) which, in turn, leads to the likelihood of deviant behaviour'.

Owing to the novelty of behavioural risk management perspective, there is a need to consolidate extant literature relevant to the measures applied for managing conflict of interests in professional accounting firms. With a specific focus on accounting professionals' behaviour in the events of conflicting interests, the second section on research synthesis will present the framework for reviewing, interpreting and analysing literature and will include literature that can potentially inform the establishment of context, assessment, treatment, control and monitoring of conflict of interests. Analysis of literature will be elaborated in the third section, followed by identification of the 'gaps in literature' in the fourth section. Finally, this paper will be concluded in the fifth section.

\section{Research Synthesis}

\subsection{Framework for Reviewing, Interpreting and Analysing Literature}

The framework for synthesising extant literature draws on the integration of the Risk Management Framework by ISO 31000:2009 and the International Code of Ethics for Professional Accountants by International Ethics and Standards Board of Accountants - IESBA.

According to ISO 31000:2009, risk management process includes four main stages, i.e. establishing the context for risk management, assessment of risks, treatment of risks, and control 
and monitoring. Since this paper is looking at the conflict of interests through the lens of risk management, the risk management framework is of relevance (ISO 2009). Moreover, the Code of Ethics provides that compliant professional behaviour is about compliance with five fundamental principles of professional ethics, i.e. integrity, objectivity, professional competence \& due care, confidentiality and professional behaviour. The code also recognises various threats, i.e. selfinterest (i.e. due to financial or other personal interest), self-review (i.e. when professionals have to review their own work), advocacy (i.e. when professionals promote client position), familiarity (i.e. due to long-term or close firm-client relations) and intimidation threat (i.e. due to actual or perceived pressures) to compliance with fundamental principles, in general, and to the professional's independence, in particular. To counter the likely devastating impact of these threats, some safeguards are created by profession and legislation, and some exist in the work environment of accounting firms (IESBA 2015, 2018).

A closer insight into the code of ethics for professional accountants and the risk management framework reveals convincing similarities and connection between the two. For instance, the code also follows a risk-based approach and involves identification and evaluation of threats to compliance with fundamental principles of professional ethics. If the threats are at an acceptable level, there is no need to apply safeguards. However, if the threats are at an unacceptable level, safeguards have to be applied to ensure that these are eliminated or are brought to an acceptable level. The said approach is exactly in accordance with the entire risk management process. Importantly, the code of ethics suggests that compliance with fundamental principles of professional ethics constitutes compliant behaviour, i.e. the primary interest of the accounting profession. Similarly, the threats to compliance with fundamental principles serve as the sources 
of secondary interest that interfere with primary interest and give rise to a conflict of interests - a risk that compliant behaviour will be compromised (IESBA 2018; Johnson and Hansen 2011).

Figure 1 presents the framework that serves as a thematic guide to be adopted for reviewing, interpreting and analysing the literature that informs management of conflict of interests in professional accounting firms.

\section{Insert Figure 1: Framework for Literature Review, Interpretation and Analysis here}

As per the framework, the risk management process for a conflict of interests begins with the establishment of context for the entire process. Next, the identification, analysis and evaluation (i.e. assessment) of conflict of interests follows - these steps address the threats to compliance with primary interest. Finally, the treatment and control and monitoring of the procedures meant to deal with conflict of interests follow - these steps involve the application of safeguards to ensure that conflict of interest has been managed in accordance with the context. The framework also highlights that control and monitoring measures are reviewed and improved continually and the context adjusted accordingly. It must, however, be noted that the same literature study might inform more than one stages in the framework. Moreover, the classification should be considered as being subjective and based on the researcher's discretion.

\subsection{Establishing the Context for Managing Conflict of Interests}

The literature in this section will highlight the main parameters that are of direct relevance to professional accounting firms for establishing an appropriate context for managing conflict of interests. In this regard, studies and provisions related to various internal and external regulations 
that have emerged over the past decade, especially in response to numerous corporate scandals, will be included.

\subsubsection{Quality Control Reviews and Inspections}

Regulators have declared the ex-post engagement reviews mandatory and they see such reviews and inspections (such as within-team reviews, engagement quality review, and peer review) as potential deterrents to the lapses in audit quality (Bedard et al 2008). The purpose of such reviews is to ensure that the firms' personnel comply with the profession's standards and that of the firm's own standards of quality. In this regard, Hatfield et al (2011) asserted that one of the potential benefits of engagement quality reviews is that these tend to reduce the instances of a tendency to focus more on confirmatory than on disconfirming evidence. However, engagement quality control review must be completed before the audit report is issued. Regarding the peer reviews, Deis and Rose (2011) provided that accounting firms undertaking these reviews tend to conduct higher quality audits and this trend of improvement continues over time with continued participation in peer reviews.

Nonetheless, the extent to which peer reviews detect problems in reviewed engagements is yet to be researched more. Furthermore, regulatory quality control reviews and inspections are conducted by government regulators with a focus on examining if the firm complies with professional standards. The quality reviews are, primarily, conducted after the audit and other accounting engagements - however, the accounting firms tend to consider these regulatory requirements before commencing the process of managing risks. This is because the establishment of context for risk management demands to take into consideration the applicable rules and regulations. 
Accordingly, the awareness and information of applicable quality control reviews and inspections are fed into the process of managing conflict of interests.

\subsubsection{Codes of Conduct}

Contextual factors such as professional or organisational norms have widely been agreed to affect ethical decision-making. Some researchers (Adams et al 2001; Bazerman and Gino 2012; Weaver and Treviño 2001) assert that the normative tone is reflected through the codes of conduct and the moral guidelines issued by management in organisations. Similarly, based on the ethical codes of conduct, employees form their perceptions of ethical climate and of how peers would do in a similar situation (Fatemi et al 2018; Jones et al 2003; Shafer et al 2001). This implies that welldrafted ethical codes of conduct have the power to influence ethical behaviour and the way professionals would handle conflict of interests. Clements et al (2012) critically examined the conflict of interests in the accounting profession and strongly asserted that firms should improve their codes of conduct for their provisions regarding prioritisation of interests.

Similarly, Douglas et al (2001) emphasised the significance of organisational values as reflected in the codes of conduct. They held that organisational values are of immense importance in professional accounting firms and that these values are taken as a means of control. However, it is not enough to just chalk out the codes of conduct because their purpose is fulfilled with employees following it. In this regard, the symbolic nature of ethical codes of conduct has been examined in some previous studies (see, for example, Citron 2003; Preston et al 1995). Therefore, extant literature suggests that the correct establishment of context for managing conflict of interests requires professional accounting firms to be aware of the internal codes of conduct. Such codes are relevant throughout the process of managing conflict of interests and especially when 
establishing the context. This is because the culture and standards prevalent in professional accounting firms play an indispensable role in defining the scope of the program to manage conflict of interests, the policy for managing conflict of interests and the risk criteria.

\subsubsection{Ethics and Compliance Programs}

Florio (2012) has regarded the conflict of interests as the virus. The author asserted that the best antidote for the harms caused by the conflict of interests is the strong ethics programmes, as well as a strong internalised sense of ethics by everyone in an organisation. He maintained that a good ethics and compliance programme is essential for the conflicting interests identified and prioritised by the firms. Other suggestions for developing an effective ethics and compliance programme included: establishment of standards and procedures, making specialised committees to oversee governance structure, education and training to manage conflict, developing an appropriate risk management framework, careful design of incentives that align with the ethics and compliance programme and necessary amendments in ethics and compliance programmes.

Similarly, for effective management of conflict of interests, Williford and Small (2013) also favoured the establishment of a strong ethics and compliance program. Particularly, they recommended that the steps issued by Federal Sentencing Guidelines for guidance on prevention of conflict of interests should be incorporated in the design and implementation of compliance and ethics program. These steps include standards and procedures (codes of ethical conduct and conflict of interests' policy), organisational leadership and a culture of compliance (tone at the top), efforts to exclude prohibited persons (due diligence), training and communication (education and awareness), monitoring, auditing and evaluating program effectiveness (program evaluation), 
performance incentives and discipline (recognition and enforcement) and remedial action (prevention and risk assessment).

With specific reference to the association between leadership and conflict of interests, Florio (2012) maintained that, to address the conflict of interests, there is an immense need to establish effective processes that should be executed under strong leadership. Furthermore, the top managers can take some steps to reduce ethical dilemmas amongst their subordinates such as by being the role models and enforcing an ethical code of conduct. Therefore, having strong ethics and compliance programs is directly relevant to the entire process of managing the conflict of interests. At the stage of establishing the context for managing conflict of interests, professional accounting firms need to take into consideration the ethics and compliance programs and implement these as an eminent part of the entire risk management process.

\subsubsection{Organisational Culture}

According to Florio (2012), managing the conflict of interests requires far more than just a strong compliance programme, and that the organisational culture should reinforce ethical conduct and not tolerate anything that casts doubts on high ethical standards. Some researchers (Jones et al. 2003; Shafer et al. 2001) found that ethical climate largely affects accountants in their ethical reasoning process. In a laboratory study, Booth and Schulz (2004) found that the individual's behaviour moves in the same direction as that of the ethical climate of an organisation. Similarly, Douglas et al. (2001) suggested that the ethical tendencies of accountants are also affected by the organisational culture. The impact of managerial philosophy on behaviour has also been researched widely. When the philosophies of managers and supervisors emphasise social and 
ethical responsibilities, employees are more likely to behave ethically. Similarly, when the philosophies emphasise profits, employees are more likely to engage in unethical behaviour.

Furthermore, the relationship between the contingencies of reinforcement and ethical decisionmaking behaviour has also been supported by various researchers (e.g. Stead et al. 1987; Worrell et al. 1985). While emphasising the importance of tone at the top, Caldarelli et al. (2012) strongly asserted that the role of ethics originates in a commitment of the top management for an ethical culture. Similarly, Treviño et al. (2003) asserted that because executive leaders of a firm have the potential to influence the employees and organisational behaviour, they play an extremely important role in shaping the ethical environment. Overall, extant literature demonstrates that executives of an organisation shape the ethical environment by setting an ethical tone at the top (see Bobek and Radtke, 2007).

Therefore, extant literature asserts establishment of strong ethical culture as a precursor to defining the scope of the program to manage conflict of interests, forming the policy for managing conflict of interests and outlining the risk criteria. The relevant literature also provides that the importance of firms' culture begins with the establishment of context and continues throughout the entire process for managing conflict of interests that accounting professionals face.

\subsection{Assessment of Conflict of Interests}

The extant literature provides that when carrying out identification, analysis and evaluation towards the management of conflict of interests, the issues surrounding independence of an accounting professional are part and parcel of the entire process. With reference to the framework for reviewing, interpreting and analysing literature (figure 1), it is pertinent to consider how the various threats might impair the independence of an accounting professional. The literature 
relevant to the assessment of conflict of interests is primarily focused on the independence of an accounting professional. This is because the conflict of interests and the independence are discussed in conjunction with one another (Bazerman and Gino 2012; Dopuch et al. 2003; Guiral et al. 2010; Moore et al. 2006; Nelson 2004).

This section will include literature that relates to the identification of the internal and external sources, causes and the potential consequences of conflict of interests (i.e. identification). Studies informing the process used to understand the nature, sources, and causes of the identified sources and to estimate the likelihood of occurrence of conflicting interests (i.e. analysis) will also be reviewed. Furthermore, literature informing the professionals' evaluation if the conflicts of interests are acceptable or need treatment (i.e. evaluation) will also be discussed.

\subsubsection{Commercial Origin of Conflict of Interests}

This part includes the review of studies that discuss the origin of conflict of interests due to the shift in accounting firms from professionalism to commercialism. In his study about ethics and accounting firms, Pierce (2007) discussed that the increasing commercial pressures, such as due to the corporate merger movement of the 1960 s, gave rise to dysfunctional consequences for accounting firms. Such dysfunctional consequences included prioritisation of client satisfaction over professional standards (Sánchez-Medina et al. 2019) and of maximisation of profit/fee over audit quality. Some researchers (Boyd 2004; McMillan 2004; Pierce 2007; Reinstein and McMillan 2004; Young 2005) agree on a stance that the corporate merger movement of the 1960s put stress on the ability of accounting firms to retain professional integrity. Merging corporations retained one of the two previous auditors and resorted to opinion shopping (i.e. the practice of 
searching for an external auditor who would provide an unqualified opinion). The accounting firms, resultantly, became commercialised and were perceived to be serving the clients' interest.

The merger activity within the accounting profession itself in the 1970s and 1980s (such as, the merger of big eight to form the then big five) also distorted their professionalism. The objective of such a merger, according to Boyd (2004), was to achieve bigger revenues, the concentration of power, and the ability to push the competition out from consultancy and management advisory enterprises. Thus, the firms began organising them in business-like structures, with client satisfaction as their priority (Boyd 2004; Stumpf et al. 2002). Further to the aforementioned devastating impacts of commercialism in accounting firms, several research studies (see, for example, Boyd 2004; Pierce and Sweeney 2004) asserted that commercial pressures also deteriorated audit quality. These studies indicate that the shift from professionalism to commercialism made accounting firms deviate from their professional duties, which also implies a deviation from compliant behaviour or from serving in the best interest of the public.

Many researchers (Beattie and Fearnley 2002; Boyd 2004; Espinosa-Pike and Barrainkua 2016; McMillan 2004; Pierce 2007; Reinstein and McMillan 2004; Stumpf et al. 2002; Young 2005) posited that commercial pressures led accounting firms to provide non-audit services which in turn created the conflict of interests for the professionals. Therefore, commercialism is considered one of the root causes of deviation from professionalism and it comes with many dysfunctional consequences. Similarly, research in this area has implications for professional accounting firms to increase their efforts towards managing conflict of interests across any threats to their professionalism. The commercial origin of conflict of interests in professional accounting firms is, therefore, of direct relevance to the identification, analysis and evaluation of conflict of interests. 


\subsubsection{Structural Origin of Conflict of Interests}

Various researchers have used archival, analytical and behavioural methodologies to examine the issues surrounding independence risk. The main issues include long term relation with clients, employing former auditors, provision of non-audit services, and compensation of partners. Although these concerns are managed before accounting firms take up the engagement, they do have an effect on a professional's conduct during the engagement. The following sub-sections will include literature regarding the origin of conflicting interests in professional accounting firms due to the various structural features.

\subsubsection{Client-Firm Relation}

Independence concerns, primarily, arise from a close relationship with client management and the keenness of accounting firms to please clients for maintaining the stream of fees (Arel et al. 2006). Both the archival and behavioural studies have focused on the tenure of an accounting professional. Overall, archival studies remain inconclusive of the association of tenure of the audit firm and that of audit quality. For instance, Deis and Giroux (1992) found that the tenure of audit-client relationship is positively associated with conflict of interests and the subsequent reduction in audit quality and provided that the longer audit tenure leads to poor audit quality. On the contrary, Geiger and Raghunandan (2002) examined the association between the type of issued audit opinion and the length of audit tenure. They found more audit reporting failures in the early years of firm-client relationship and suggested that partners' rotation might not be beneficial. Similarly, Johnson et al. (2002) also supported the stance that longer the auditor tenure, the better the financial reporting.

Behavioural research, however, seems to support the rotation of accounting firm partners. For instance, Dopuch et al. (2001) used experimental methods to examine the extent to which auditor 
independence is affected in different regimes of rotation and retention of accounting firms. They found that the auditors tend to be more biased in favour of clients during the regimes that do not require rotation. Similarly, Favere-Marchesi and Emby (2005) reported that compared to new concurring partners, the continuing concurring partners are less likely to conclude that purchased goodwill might be impaired. Moreover, Hatfield et al. (2011) examine the impact of prior audit involvement and client pressure on proposed audit adjustments and concluded that partners' rotation has positive effects on audit quality. Overall, the behavioural studies associate long tenure of audit-client relationship to poor audit quality.

Although the direction of the association between long term client-firm relationship and audit quality remains inconclusive, both the archival and behavioural research indicates that the longterm relationship of clients and professional accounting firms might threaten audit quality due to the conflict of interests. Literature indicates that in situations like the long-term relationship between the client and the firm, various threats are likely to arise including self-interest and familiarity threats.

\subsubsection{Employing Former Accounting professionals}

Prior to the collapse of Enron in 2001, it was a common practice amongst clients to hire the former accounting professionals from the firms auditing their statements. The common reason for clients to do so was, arguably, to benefit from the hired professional's knowledge of clients' business, their understanding of financial reporting process and other information systems (Beasley et al. 2000). This practice, however, was discouraged with the implementation of Sarbanes-Oxley Act (SOX) in 2002 that required clients to not hire from their former auditors for up to a period of oneyear, post-audit, termed the cooling-off period (Ahmad 2015). The employment of the members 
from the engagement team is of concern to managing conflict of interests due to the possibility of impaired independence in such situations. Koh and Mahathevan (1993) found that the perceptions of loss of independence were higher for shorter cooling-off periods and argued that employment opportunities with clients might induce the accounting professionals to serve client's interests due to their impaired independence.

Other researchers (see, for example, Beasley et al. 2000; Menon and Williams 2004) used archival methods to examine the possibility of impaired independence in cases where clients employ former accounting professionals. These studies agree that such employment of former professionals is likely to result in loss of independence as well as the loss of professional scepticism and that the employment opportunities with clients might induce the accounting professionals to serve client's interests. However, Geiger et al. (2005) did not find any evidence that the hiring of former accounting professionals is associated with aggressive financial reporting on account of impaired independence. The International Federation of Accountants (IFAC) associates the hiring of former auditors as giving rise to the self-interest and familiarity threats. The threats further give rise to a deviation from serving the primary interest of the accounting profession (Ahmad 2015) and imply the presence of a conflict of interests.

Overall, the literature indicates that in situations like the hiring of former accounting professionals, various threats are likely to arise including self-interest, familiarity and intimidation threats.

\subsubsection{Provision of Non-Audit Services}

One of the widely researched topics relevant to conflict of interests in professional accounting firms is to examine whether the provision of non-audit services results in impaired independence and audit quality. Under certain circumstances, professional accounting firms are permitted to 
provide non-audit services. However, based on a principle that provision of non-audit services harms the actual or perceived quality of an audit, the current rules under SOX prohibit the accounting firms from providing some non-audit services (Bedard et al. 2008). Some researchers (Boyd 2004; Citron 2003; Frankel et al. 2002) have reported the provision of non-audit services as a threat to accounting professionals' independence. Numerous other studies have also associated the provision of non-audit services directly with conflict of interests. In this regard, several researchers (Boyd 2004; McMillan 2004; Pierce 2007; Reinstein and McMillan 2004; Young 2005) support the stance that commercial pressures led accounting firms to provide non-audit services which in turn created the conflicts of interests for accounting professionals.

The stance that higher fees for non-audit services induce firms to provide non-audit services and thereby creates a conflict of interests is supported by various researchers (Frankel et al. 2002; Ruddock et al. 2004). Although, some researchers (Craswell et al. 2002; Defond and Francis 2005; Skaife et al. 2003) do not support the view that higher non-audit fee affects the issued audit opinions. However, most of the studies report a direct association between the two variables. Still others (Kinney et al. 2004; Sharma and Sidhu 2001) supported this association in certain circumstances.

Furthermore, with reference to the harms of threatened independence and the provision of nonaudit services, Bazerman and Gino (2012) suggested that by providing non-audit services to the clients, the auditors open themselves to the criticisms of subjectivity, compromising their independence and the prioritisation of public interests. They provided that provision of non-audit services to the clients leads to biased decision-making. Overall, the research relevant to the provision of non-audit services suggests that such arrangements give rise to the conflict of interests in professional accounting firms. Importantly, Beattie and Fearnley (2002) provided that the 
provision of non-audit services gives rise to the self-interest, self-review, advocacy and familiarity threats.

\subsubsection{Hiring and Firing of Professional Accounting Firms}

The hiring and firing of auditors by the clients are believed to create a conflict of interests that tends to impair the auditors' independence (Bae et al. 2013; Mayhew and Pike 2004; O'Connor 2006; Ronen 2010). Similarly, because the decision to hire and fire the accounting firms rests with clients, the members of the engagement team are perceived as not being independent in their conduct. According to Moore et al. (2006), the accounting firms have incentives to avoid the provision of negative audit opinion about clients who hire them. Therefore, in such a situation, accounting professionals are perceived to be dependent on their clients.

With particular reference to the practice of opinion shopping and the role of audit committees, Lennox (2003) provided that hiring and firing of auditors is the responsibility of client's audit committee which supposedly works independently of the client's management. In practice, however, the management exerts considerable influence on hiring and firing of the external auditors such that the audit committee's authority is compromised. Thus, the committee's decision to hire and fire is largely affected by management's preferences in this regard. Literature indicates that since clients have the power to hire and fire accounting firms, they are likely to have considerable influence on how the services are provided by professional accounting firms. Therefore, in situations like this, various threats to compliance with fundamental principles of professional ethics are likely to arise including self-interest, advocacy and intimidation threats.

\subsubsection{Workplace Pressures}


Workplace pressures have been associated with various dysfunctional practices that include a wide range of behaviours which not only threaten the quality of audit but also encourage the provision of non-audit services in the best interest of clients (Espinosa-Pike and Barrainkua 2016). In both instances, the primary interest of the accounting profession is believed to be compromised (Pierce 2007). One strand of research highlights various dysfunctional behaviours committed by professionals such as not testing fully the required number of samples and the falsification of working papers (Sikka 2004), premature signing-off on audit assignments (Otley and Pierce 1996), inadequate paperwork and under-reporting of audit hours by the auditors in order to avoid budget overruns (Anderson-Gough et al. 2001).

Another strand of research tends to examine the causes of such dysfunctional behaviours. For instance, several researchers (see, for example, Boyd 2004; Pierce 2007; Pierce and Sweeney 2004) attributed commercial pressures faced by accounting firms to a reduction in audit quality. Some agree that dysfunctional behaviours are an outcome of various other workplace pressures that the professional face, such as time pressure due to the tight deadlines and time budgets given to accounting professionals (Anderson-Gough et al. 2001; Sikka 2004) and the obedience pressure (Davis et al. 2006). For instance, because articling students and juniors want to excel in a career, they face pressure to deliver within a highly limited time (i.e. time pressure) and pressure to obey seniors (i.e. obedience pressure).

According to Boyd (2004), workplace pressures in accounting firms have their roots in the practice of opinion shopping. The authors discussed that as the organisations began resorting to price-shop (opinion-shop) for audit services, accounting firms realised that the controllable variable at their disposal was the price. They had to offer audit services at a cheap price and in order to cut the cost of auditing, the firms had two main option i.e., either by reducing labour-hours devoted to audit or 
by reducing cost per labour hour. Accordingly, the accounting firms reduced their costs by dedicating highly limited hours to audit and non-audit services and by hiring the low-cost auditors (such as articling students or junior auditors) - in both the cases, audit-quality deteriorated. Therefore, various pressures made the accounting professionals deviate from the primary interest of serving in the best interest of the public.

Thus, literature draws attention towards the fact that many pressures originate from within the work environment in professional accounting firms and resultantly, many threats arise that serve as secondary interest for an accounting professional. For instance, given the tight deadlines, a junior professional might compromise the quality of work in order to secure the chances of progression in a career (self-interest threat) and a professional might feel pressurised to act in accordance with their senior's priority to serve the clients' interests (i.e. intimidation threat). Therefore, various workplace pressures threaten professionals' conduct and act as the sources of secondary interests and, hence, have relevance to the assessment of conflict of interests.

\subsubsection{Reward Systems}

Reward systems are meant to motivate performance in a particular way. In this regard, the main motivators used by organisations to encourage certain behaviour include goal setting, acknowledgement of employees' achievements, a delegation of authority, and monetary rewards (Amali 2010). Such reward systems, however, have been associated with conflict of interests in professional accounting firms. For instance, Pierce (2007) reported that a number of conflict of interests in accounting firms originated within their marketing and sales activities that were encouraged by internal reward systems and cultural norms of the firms. Likewise, Goto (2004) also investigated the association of rewards structures with ethical behaviour and found that the 
right reward structures were positively related to ethical behaviour. Furthermore, Green and Zimiles (2013) provided that most of the conflict of interests with reference to reward systems involve financial motives but may also involve advancement and recognition.

Arguably, even if the accounting firm has a good reputation and high standards, individuals within the firm may be inclined to give in to the pressure from clients and engage in behaviour that is not in accordance with the ethical standards. The motivational and control structures in an organisation are of immense importance in aligning the goals of individual accounting professional with that of the firms (Fearnley et al. 2002). Amali (2010) found that the immediate causes of unethical behaviours include incorrect implementation of motivators, simultaneous use of motivators, and the absence of appropriate controls within the workplace. Thus, misaligned rewards can be regarded as one of the sources of conflicting interests in an accounting profession.

Similarly, Wyatt (2004) asserted that the internal culture of greed within the firms gives rise to employees' behavioural changes and that no legislation can solve the problem unless firms themselves make efforts. Strong leadership is required to bring about a reversal of such behavioural changes. Likewise, Schminke et al. (2007) argued that it is necessary to encourage an environment where ethical behaviour is rewarded. Emphasising the power of leaders in this regard, they asserted that the organisational leaders should act with moral sensitivity and must have an ability to sympathise with employees facing ethical dilemmas.

The aforementioned literature studies suggest that the rewards misaligned with the primary interest of the accounting profession threaten compliant behaviour and can be regarded as one of the broad sources of conflict of interests. The main threats that professionals face in such situations include 
self-interest, self-review and advocacy threats. All such situations involving misaligned rewards have important implications towards identification, analysis and evaluation of conflict of interests.

\subsubsection{Bias due to Conflict of Interests}

Literature regarding bias due to conflict of interests tends to focus on the psychological and cognitive barriers experienced by individual decision-makers. Studies in this domain revolve around the idea of limitations on the conscious mind and the power of the unconscious mind, both of which are central to making ethical decisions involving the conflict of interests. The central idea is that, when making the decisions, individuals overestimate the influence of their own intentions and underestimate the power of automatic processes outside of our consciousness (Casebeer and Churchland 2003; Damasio 2006; Moll et al. 2005). For instance, Wagar and Thagard (2004) addressed the moral psychology of conflict of interests and developed a decision-making model, i.e. 'GAGE Model' that draws on cognitive-affective integration during ethical decision-making. This model posits that ethical decision-making and reasoning is neither purely cognitive nor purely affective but is a combination of both. These studies have important implications to explain why, in the face of a conflict of interests, the deviations from ethical behaviour might occur undesirably.

Moore, Tetlock, Tanlu and Bazerman (2006) used Moral Seduction Theory to explain why accounting professionals are unaware of how morally compromised they have become due to the conflict of interests. According to them, potential threats to the independence of auditors are posed by three structural features i.e. hiring and firing of auditors by clients, auditors taking jobs with clients, and simultaneous provision of audit and non-audit services. The authors asserted that in the presence of these structural arrangements, auditors become morally seduced to serving selfinterests due to some cognitive barriers such as unconscious bias due to conflict of interests, 
selective perception, barriers posed by workplace pressures and the barriers imposed by partners who prefer maximising the billable hours.

Similarly, the ethical decision-making research that draws on cognitive models (Guiral et al. 2010; Rodgers 2006, 2009; Rodgers and Gago 2001, 2006) asserts the importance of cognitive approach for understanding the process through which conflict of interests affect decision-making behaviour in professional accounting firms. Accordingly, a decision in a given situation is an outcome of interaction information, perception, judgement and decision choice. During the course of this interaction, the individual's perceptions interfere with information and/or judgement to produce biased decisions. With reference to the management of conflicting interests in professional accounting firms, Guiral et al. (2010) developed a cognitive approach by connecting Throughput Model to Moral Seduction Theory. They examined the role of perceptions in professionals' decision-making and found that conflict of interests resulted in unconscious bias due to the significant role of perceptions. Similarly, Ishaque (2019) integrated Throughput Model with Social Cognitive Theory and provided empirical evidence that decision-making behaviour, in situations involving a conflict of interests, is largely driven by the unconscious perceptual bias.

Likewise, Chugh et al. (2005) drew attention towards the impact of psychological barriers on ethical decisions involving a conflict of interests. The authors asserted that ethical decisions are biased by psychological barriers on one's mind that are characterised by a stubborn view of oneself that one is ethical, deserving, and competent and thus not susceptible to conflict of interests. Such barriers, according to the authors, increase the risk that otherwise visible conflict of interests will not be recognised by that person. Closely related are the studies examining decision-making in the face of ethical dilemmas (see, for example, Casebeer and Churchland 2003; Greene et al. 2001; Green et al. 2010). The recurring theme of these studies is that the decision outcome in any given 
situation is affected by the decision-makers' subjective experience of a given dilemma or similarly, the conflict of interests' situations.

Furthermore, highlighting the significance of employees' perceptions regarding the ethical codes of conduct, some researchers (see, for example, Jones et al. 2003; Shafer et al. 2001) assert that employees form their perceptions of ethical climate and of how peers would do in a similar situation. Likewise, the role of ethical predispositions and cognitive moral development as sources of bias in decision-making has also received the attention of researchers. For instance, Ashkanasy et al. (2006) found that the managers with low cognitive moral development who perceived that their organisations overlooked unethical behaviour made less ethical decisions. Importantly, literature regarding bias due to conflict of interests provides that situations involving a conflict of interests give rise to, largely, the unconscious bias in the decision-making process. However, due to the direct impact of perceptions on decision-making, the presence of conflicting interests might lead an auditor to engage in intentional corruption as well (Chugh et al. 2005; Guiral et al. 2010; Rodgers 2006, 2009; Rodgers and Gago 2001, 2006).

With particular reference to identification, analysis and evaluation of conflict of interests, the extant literature draws attention towards the need for taking into consideration the role of professionals' unconscious perceptual biases, psychological and the cognitive barriers towards compliant decision-making. Since these provisions have to do with the professionals' state of mind, these are directly relevant to their independence in fact. As evidenced through the aforementioned studies and other relevant neuroscience literature (see, for example, Cotterill 2000; Damasio 1994, 2003; Haidt 2001; Lakoff and Johnson 1999; Panksepp, 2009), the real challenge lies in the fact that ethical decision-making is intuitive and dominated by the unconscious emotional processes. Importantly, Panksepp (2009) drew attention to seeking a solution in the 
unconscious. These studies imply that the accounting profession will be able to manage conflict of interests only if the professionals' unconscious mental processes, in addition to the more known conscious cognitive obstacles, are duly considered.

\subsection{Treatment, Control and Monitoring of Conflicting Interests}

This section will include literature that informs treatment, control and monitoring of conflict of interests in professional accounting firms. In this regard, literature will particularly be examined for the safeguards created by the accounting profession, legislation and regulation and the safeguards in the work environment of the professional accounting firms

\subsubsection{Codes of Ethics}

The codes of ethics are implemented as one of the preliminary safeguards for treating, controlling and monitoring the conflict of interests. Various accountancy bodies (including AICPA, NASBA, AAT, ACCA, ICAEW, CIMA, CIPFA, ICAS and CAI $)^{1}$ have built their codes of ethics on the principles of the Code of Ethics for Professional Accountants 2015 and the International Code of Ethics for Professional Accountants 2018. These codes, therefore, adopt the 'threats \& safeguards approach' for strengthening compliance with the fundamental principles of professional ethical conduct, i.e. integrity, objectivity, professional competence and due care, confidentiality and the professional behaviour. Importantly, the codes of ethics provide extensive provisions for minimising risks to the professionals' independence (IESBA 2015, 2018; Johnson and Hansen 2011).

Some studies in the professional accounting context have attempted to establish the relevance of the codes of ethics to address the conflict of interests and independence issues. Highlighting the 
impact of ethical codes of conduct on professionalism, Fatemi et al. (2018) support the idea that codes of ethics have a positive impact on the professionals' judgement. An earlier study by Cowton (2009) examined if the codes of ethics, implemented by the professional accounting bodies, are effective in encouraging ethical behaviour. The findings suggested that although the codes of ethics contribute towards creating a decent moral community, these cannot be perfect and should be combined with other measures for managing the conflict of interests. Other studies (see, for example, Duska et al. 2011; Flanaga and Clarke 2007) also support this stance.

Thus, the extant literature on the codes of ethics as a safeguard for managing conflict of interests provides that the codes are an effective tool for treating, controlling and monitoring the conflict of interests. However, there is a need for other complementary measures because the codes alone cannot fix all the problems surrounding the accounting professionals' independence.

\subsubsection{Electronic Decision Aids}

Accounting firms use electronic decision support systems in order to exercise centralised control and monitoring over risk management practices in relation to engagement performance and independence concerns. The primary reason to employ such decision aids was to improve the quality of decisions, especially those related to ex-post engagement review and inspection (Bedard et al. 2008). Supporting the use of electronic decision aids, Pierce and Sweeney (2004) provided that compared to paper files, the electronic files improved monitoring of the actions of accounting professionals. Dowling (2009) discussed the benefits of and barriers to the implementation of electronic decision aids and work systems in global accounting firms. Accordingly, the main benefits of these systems were reported to be the improvement in risk management, better control on staff, better compliance with firm's audit methodology, consistency in audit approach, 
enhancement in audit quality due to increased compliance with professional accounting standards, increase in efficiency of audits, and improved documentation.

Following the examination of the impact of information technology (IT) on the productivity of accounting firms, Banker et al. (2002) reported increased efficiency due to the implementation of IT. Electronic decision aids, however, have also been discussed for their limitations in practical usefulness. For instance, the main barriers and costs associated with their implementation include over-reliance on systems recommendations, emphasis on ticking-the-box, training to use electronic systems, less cost efficiency for smaller engagements, and restricted use due to perceived difficulty. Such barriers might cause a professional to misuse the system such as, selection of input parameters that will favour the desired outcome (Dowling 2009). Some researchers (Bedard et al. 2003; Bedard et al. 2006; Bedard et al. 2008) believe that provision of appropriate training to the professionals will help overcome the said limitations of electronic systems.

With reference to the treatment, control and monitoring towards management of conflict of interests, literature suggests that the electronic decision aids play an important role as a safeguard and inform decisions about avoiding the situations involving conflict of interests, accepting the identified conflict of interests, sharing these with other parties, or reducing the conflict of interests to an acceptable level. Furthermore, electronic aids also seem to support the implementation of controls and continual supervision to determine if the controls are being executed properly.

\subsubsection{Consultation Units}

One of the ways for accounting firms to control risks is by developing specialised internal groups to assist practice offices in making decisions related to the financial statements of clients. These groups are termed Accounting Consultation Units (ACU) or Central Research Units (CRU) that 
provide potential benefits to the professional accounting firms. The main benefits include financial support, consultation, documentation and research aimed at suggesting better solutions for the client's accounting problems. These units are very well-formed especially in larger firms and provide an array of services. Importantly, firms view the consultation and research units as playing an important role (Bedard et al. 2008). Given the complexity and nature of negotiations between accounting firms and the clients, several researchers (Iyer and Rama 2004; Kadous et al. 2003; Trotman et al. 2005) tend to favour investment in such ACUs.

Thus, the accounting consultation and research units are likely to be of significant use to the accounting professionals. Their utilisation, however, differs with the size of the firm with more well-organised functioning in larger accounting firms. Therefore, the literature indicates that consultation units have an important role to play as one of the safeguards in connection with effective management of conflict of interests, particularly at the stages of treatment, control and monitoring. For instance, the research unit can help find better solutions to address the conflict of interests that are likely to originate throughout the course of professional conduct.

\subsubsection{Whistleblowing}

Since whistleblowing is about making disclosure in public interest, there is an indispensable connection between whistleblowing and accounting profession since the primary interest of the later is also to serve in the best interest of the public. The Sarbanes-Oxley Act (SOX) of 2002 requires the audit committees of public companies to form whistleblowing mechanisms in order to enable the employees to raise their concerns about questionable accounting matters, with anonymity and confidentiality. According to the information collected through surveys, $\mathrm{PwC}$ (2005) provided that whistleblowing mechanisms increased the likelihood of employees' reporting 
about wrongdoings. Since its passage in 2002, SOX has extended its rulings on whistle-blowers' protection. The strengthening of said protection is of relevance to the accounting professionals since they have an important role as an implied whistle-blower, should they find any instances of their clients' fraudulent conduct (Bedard et al. 2008).

Literature suggests that propensity of an accounting professional to blow a whistle on wrongdoings is strongly affected by the context in which wrong conduct takes place (Ayers and Kaplan 2003; Near et al. 2004; Latan et al. 2019). The likelihood of whistleblowing is also affected by individual characteristics such as the perceptions of whistleblowing, moral reasoning, individual's sense of responsibility, locus of control, whistleblowing intentions, perceived moral intensity and position in the firm (Chiu 2003; Curtis 2006; Latan et al. 2019; Tavakoli et al. 2003). Furthermore, the organisational characteristics and organisational culture also affect whistleblowing behaviour (Kaplan and Whitecotton 2001).

Thus, research suggests that whistleblowing mechanisms can be an effective way to control the audit-related risks. Their effectiveness, however, is largely affected by the individual, contextual and organisational factors. Importantly, employees are more likely to blow the whistle when confidentiality is ensured, a mechanism to whistle-blow are properly understood, and training is provided in this regard. Therefore, whistleblowing is an important safeguard in relation to managing conflict of interests in professional accounting firms, particularly at the stages of control and monitoring.

\subsubsection{Reviews and Inspections}

The main quality control inspections and ex-post engagement reviews examined in extant literature include engagement quality control reviews, peer reviews, regulatory quality control inspections 
and reviews. Over the past two decades, the regulators have made these reviews mandatory, and from being conducted by peers to the regulators. These shifts evidence that the regulators consider such reviews as potential facilitators of audit quality. The literature demonstrates that engagement quality control reviews help in reducing audit risk in different ways. For instance, these reviews help improve the assessments of audit risk (Ayers and Kaplan 2003), tend to reduce the instances of a tendency to focus more on confirmatory than on disconfirming evidence and encourage engagement personnel to conduct thorough audit tests (Tucker and Matsumura 2002). However, engagement quality control is to be completed before the audit report is issued.

With reference to the association between peer reviews and audit quality, Deis and Giroux (1992) provided that accounting firms undertaking peer review process tend to conduct higher quality audits and that this trend of improvement continues over time with the continued participation of accounting firms in peer reviews. Furthermore, regulatory quality control reviews and inspections are conducted by the government in the form of 'Desk Reviews' and 'Quality Control Reviews', with a focus on examining if the firm complies with professional standards. However, the extent to which peer reviews detect problems in reviewed engagements is yet to be researched more (Bedard et al. 2008).

Thus, the literature strongly asserts that the reviews and inspections play an important role as a safeguard in relation to the treatment, control and monitoring towards managing conflict of interests in professional accounting firms.

\subsubsection{Disclosures}

Given that the simultaneous provision of audit and non-audit services gives rise to an obvious conflict of interests in professional accounting firms, provision of some of the non-audit services 
is already barred by the regulators. For the rest, the disclosure of the provided non-audit services and the fee received is adopted as one of the ways to treat the problems associated with the actual and potential conflict of interests (Shafer et al. 2001). The proponents of disclosure policy (see Healy and Palepu 2001) believe that it tends to reduce the information gap between the informer and that informed. They asserted that disclosure facilitates market efficiency by mitigating the information gaps. Furthermore, due to the disclosure of non-audit services and the associated fee, advisees know about the advisor's conflict of interests and thus aware of the fact that they have to discount the advice in order to undertake decisions.

However, Cain et al. (2005) argue that while disclosure promises something for everyone, disclosures do not guarantee that professionals have acted in the best interest of the public, and further that they might be prone to providing more biased advice when they know that the advisee is aware of the conflict of interests. Arguably, the disclosure of non-audit services might make the public more sceptic of audit opinion and it might be perceived that there was lack of independence - in such instances, there might be independence in fact but not the independence in appearance (Moore et al. 2006). Overall, extant literature remains inconclusive about the effectiveness of disclosure of non-audit services and the associated fee as a safeguard towards managing conflict of interests. However, it seems obvious that while disclosures might be able to address the issue of independence in appearance, it cannot address independence in fact.

\section{Literature Analysis}

Now that literature in relation to the management of conflict of interests in professional accounting firms has been reviewed and interpreted in preceding sections, its critical analysis will be elaborated in this section. The analysis will be conducted across three closely related parallel 
themes that have been identified from the reviewed literature. These themes are weaknesses in professional accounting regulations for addressing conflict of interests, misaligned incentives and disincentives in a professional accounting environment and the impact of cognitive processes on an accounting professional's behaviour.

\subsection{Weaknesses in Professional Accounting Regulations}

The literature informing the establishment of context, treatment, and the control and monitoring towards managing conflict of interests makes it crystal clear that professional accounting firms are heavily regulated. The said literature draws attention towards an important question, i.e. if the accounting profession is so profoundly regulated, why is the problem of accounting professionals' deviant decision-making behaviour due to the conflict of interests largely pervasive? The discussions in proceeding paragraphs of this sub-section will address this question.

Moore et al. (2006) explained that conflict of interests results in involuntary bias rather than deliberate corruption. They argued that; since an accounting professional's moral seduction is primarily facilitated by unconscious psychological processes, increasing the regulations to strengthen their independence does not guarantee the elimination of conflicting interests. Regulations to address audit quality seem insufficient for addressing the issues related to independence because such rules are not the only ways to avoid conflict of interests. Similarly, Cain et al. (2005), Guiral et al. (2010), Moore et al. (2006) found that the conflict of interests leads to unintentional bias rather than intentional dishonesty and that more than regulatory efforts are required to monitor such conflicting interests with a focus on addressing the unintentional biases.

Clements, Neill and Stovall (2012) argued that regulations such as Sarbanes-Oxley have only remained moderately successful in countering the effects of conflicts. Based on their critical 
examination of conflicts of interest in the accounting profession, they strongly asserted that in the absence of revolutionary changes, conflicts of interest are likely to remain in the accounting profession for an indefinite future. They emphasised that accountants need to learn to identify and manage conflicts of interest and that educational efforts and professional training should be increased in this regard. Furthermore, codes of conduct should be improved for their provisions regarding prioritisation of interests. As such, this research also highlights the weaknesses in existing regulatory efforts. Therefore, the literature suggests that due to the ineffectiveness of regulations in dealing with unconscious biases, the problem of accounting professionals' deviant decision-making behaviour due to the conflict of interests is still pervasive.

\subsection{Misaligned Incentives and Disincentives}

The literature informing identification, analysis, and evaluation of conflict of interests reveals a wide range of circumstances that give rise to a conflict of interests in professional accounting firms. Particularly, the incentives and disincentives that are misaligned with compliant behaviour serve as one of the sources of conflict of interests. The said literature draws attention towards an important question, i.e. if the misaligned incentives and disincentive have been identified as one of the potential sources of conflict of interests for accounting professionals, why is the problem of accounting professionals' deviant decision-making behaviour due to the conflict of interests largely pervasive? The discussions in proceeding paragraphs of this sub-section will address this question.

A detailed review of literature (Beattie et al. 2005; Moore and Loewenstein 2004; Moore et al. 2005; Moore et al. 2006; Moore et al. 2010) and some inspections reports by Audit Quality 
Inspection Annual Reports 2011 - 2015 (Financial Reporting Council 2016) reveals the following three main sources of secondary interests for the accounting professionals.

\section{i. Misaligned Incentives with Roots in Temptation for Gain}

Various incentives with roots in temptation for gain are likely to induce accounting professionals to prioritise clients' interest over the public. For instance, the incentives to please clients and to retain them include higher fees for audit and non-audit services, job opportunities with clients, and close relationship with clients etc. With such structural arrangements, professionals are likely to face financial as well as non-financial gains including; higher fees, the possibility of a regular stream of income, and temptation for attractive job opportunities with clients. Similarly, misaligned incentives also originate from within the reward structures of accounting firms such as; performance evaluations based on pleasing and retaining the clients, bonuses paid for bringing in new clients for non-audit services and promotions of junior staff based on how well they cope with the priorities of their seniors.

In the situations as above, the secondary interests for a professional might take various forms such as; 'because I want to earn the bonus offered for pleasing the clients and thus retaining them, I should prioritise client's interest' or 'because I want the job with client, I must prioritise client's interest'. Therefore, misaligned incentives with roots in temptation for gain give rise to conflicting secondary and primary interests.

\section{ii. Misaligned Incentives with Roots in Fear of Loss}

Various incentives with roots in fear of loss (e.g. fear of losing the clients and thus the regular stream of income, loss of bonus and of the promotion opportunities etc.) are likely to induce 
accounting professionals to prioritise clients' interest over the public. Although, the misaligned incentives with roots in temptation for gain and those with roots in fear of loss are closely related and might seem exactly the same at first instance, however, with individual as a unit of analysis, research (see, for example, Gonzalez et al. 2005, Jepma and López-Solà 2014) suggests that people respond differently to what they deem rewarding and to what they consider fearsome, and that they react differently to a particular choice depending on whether it is presented as a gain or as loss framing effect.

In case of misaligned incentives with roots in fear of loss, the secondary interests for an accounting professional might take various forms such as; 'because I don't want to lose the bonus offered for pleasing the clients and thus retaining them, I should prioritise client's interest' or 'because I don't want to lose the chances of promotion based on pleasing and retaining the clients, I have to prioritise client's interest'. Therefore, misaligned incentives with roots in fear of loss give rise to conflicting secondary and primary interests.

\section{iii. Workplace Pressures with Roots in Fear of Loss}

As reviewed in the preceding section, auditing literature has associated various workplace pressures (such as commercial pressures, time pressure, time budgets, unrealistic goals, peer pressure, and obedience pressure etc.) to a wide range of dysfunctional practices. For instance, acute time pressure leads to a reduction in audit quality due to the accountants' tendency to cutting the sample sizes or reducing audit hours etc. They do so because they face various fears such as; threat to career progression in the firm, loss of bonus for failing to achieve the target in the stipulated time, and loss of reputation as an efficient employee etc. 
In the situations as above, the secondary interests for a professional might take various forms such as; 'because I don't want to lose the chances of career progression, I have to comply with the instruction of my senior that client's interest should be prioritised (obedience pressure)'. Resultantly, audit quality suffers which is tantamount to compromising the primary interest of the profession. Similarly, an in-depth insight into the International Code of Ethics for Professional Accountants (IESBA 2018) and the literature relevant to conflict of interests (see Juhari et al. 2013) suggest that the root causes underlying self-interest, self-review, advocacy, familiarity, and intimidation threats are primarily the misaligned incentives with roots in temptation for gain, that with roots in fear of loss, and workplace pressures with roots in fear of loss.

Therefore, literature suggests that due to the apparent lack of focus on root causes of conflict of interests (i.e. misaligned incentives with roots in temptation for gain, that with roots in fear of loss and the workplace pressures with roots in fear of loss) at the level of an individual professional, the problem of accounting professionals' deviant decision-making behaviour due to the conflict of interests is still largely pervasive.

\subsection{Unconscious and Conscious Aspects of Ethical Decision-Making}

The behavioural literature informing identification, analysis, and evaluation of conflict of interests tends to focus on the psychological and cognitive impacts of conflict of interests on an accounting professional's behaviour. Particularly, the simultaneous role of conscious and unconscious perceptual biases is asserted. The said literature draws attention towards an important question i.e. why despite accounting professionals' good intentions, is the problem of their deviant decisionmaking behaviour due to the conflict of interests largely pervasive? The discussions in proceeding paragraphs of this sub-section will address this question. 
Research regarding the psychology of conflict of interests (see, for example, Bazerman et al. 2002; Moore et al. 2006) suggests that various perceptual biases including; selective perception bias, escalation of commitment bias, plausible deniability, and discounting of information bias act as the barriers to compliant decision-making in the face of conflicting interests. Similarly, literature related to cognitive psychology of conflict of interest (see Guiral et al. 2010) provides that conflict of interest act through the agency of involuntary biases to affect judgement and decision-making. These studies, therefore, draw attention towards the examination of conflict of interests at the level of an individual professional accountant. Interestingly, most of the studies in relation to managing conflict of interests have focused on accounting firms as the unit of analysis.

Even more interestingly, an in-depth analysis of literature regarding structural origin of conflict of interests (see, for example, Moore et al. 2003; Moore et al. 2006; Moore et al. 2010) indicate that the structural arrangements between accounting firms and the clients (such as, long-term relationship, simultaneous provision of audit and non-audit services, hiring and firing by clients, and employment opportunities with clients etc.) exert their impact on professionals' judgement through cognitive processes in their minds and brains. All such studies imply that accounting professionals are the one experiencing a conflict of interests and, therefore, it is essential to give due consideration to psychological and cognitive perspectives to manage conflict of interests.

The behavioural literature towards assessment, treatment, and control and monitoring towards the management of conflict of interests also make their connection to the role of regulatory and legislative efforts for addressing conflict of interests. For instance, studies regarding the impact of psychological barriers on ethical decisions involving conflict of interests (see Chugh et al. 2005) and those examining decision-making in the face of ethical dilemmas (see, for example, Casebeer and Churchland 2003; Greene et al. 2001; Green et al. 2010) indicate that the existing safeguards, 
legislation and regulation have limited effectiveness towards handling the devastating ramifications of conflict of interests. Notably, this differentiation between the controlled cognitive and the automatic affective processes has long prevailed in the psychology (see, for example, Zajonc 1980, 1984; Zajonc and McIntosh 1992) and the neuroscience literature (see, for example, Damasio 2006; LeDoux 1999; Panksepp 1998, 2009; Wagar and Thagard 2004). There is growing evidence that behaviour is affected by both the controlled cognitive processes (Wolford et al. 2000) and the automatic affective processes (Bargh et al. 1996; Bargh and Chartr 1999; Schneider and Shiffrin 1977).

Similarly, Moll et al. (2005) found that ethical decision-making draws on the integration of the processes in the unconscious as well as the conscious regions of the brain. In this regard, Chugh et al. (2005) explained the phenomenon of bounded ethicality which implies that the ethical decisions involving a conflict of interests are likely to introduce bounds on conscious thinking and the biases in unconscious thinking. There, however, is a need for more research in this regard. Therefore, due to the lack of focus on the unconscious and conscious cognitive barriers that individual accounting professionals experience in the face of conflicting interests, the problem of accounting professionals' deviant decision-making behaviour is still pervasive. In this regard, Bazerman and Gino (2012) strongly assert that adoption of behavioural ethics is better than the traditional approaches.

\section{Gaps in the Literature}

Discussions of literature across establishing the context, assessment, treatment, and control and monitoring towards managing conflict of interests revealed that there is a rich literature base to inform these various stages. Although it appears that research has been done in this regard, it still 
is not enough to address the issues surrounding conflict of interests in the professional accounting environment.

The critical analysis in previous section clarifies that the problem of accounting professionals' deviant decision-making behaviour due to the conflict of interests is largely pervasive due to ineffectiveness of regulations in dealing with unconscious biases (Cain et al. 2005; Guiral et al. 2010; Moore et al. 2006), the apparent lack of focus on root causes of conflict of interests at the level of an individual professional (Ayal and Gino 2012; Bazerman and Gino 2012; Moore et al. 2010), and the lack of focus on unconscious and conscious cognitive barriers that individual accounting professionals experience in the face of conflicting interests (Bazerman and Gino 2012; Moore et al. 2010; Nelson 2004). These studies suggest that the primary reason underlying pervasiveness of professionals' deviant behaviour is the ineffective management of conflict of interests in professional accounting firms. Since decision-making in situations involving the conflict of interests is an outcome of both the conscious and the unconscious mental processes, there is a need for further empirical examination.

Interestingly, the research on the unconscious and conscious cognitions advanced research on the implications of moral intuition for ethical decision-making and organisational research (see, for example, Culham 2013, 2015; Weaver et al. 2014; Woiceshyn 2011). Even recently, there have been calls for rethinking the reasoning standard and to account for intuition in the decision-making process (Hermann et al. 2017). Still, others have noted the interplay between moral intuition and moral reasoning during ethical decision-making (see Zollo et al. 2017). These studies imply that moral intuition has implications for decision-making in the face of a conflict of interests surprisingly, professional accounting research has not sufficiently explored this topic. While some research has made a slight reference to ethical/moral intuition (Bangan and Asri 2017; Bobek et 
al. 2015; Kung and Huang 2013), there remains a significant lack of research in this regard. Thus, 'understanding the implications of moral intuition' should be one of the essentials to facilitate effective management of conflict of interests.

Therefore, the causes of the pervasiveness of deviant decision-making behaviour in professional accounting firms highlight some interconnected gaps regarding the management of conflict of interests. For instance, there is an insufficiency of research with an individual accounting professional as the unit of analysis. Secondly, there still is a lack of understanding about why, despite their good intentions, accounting professionals sometimes serve secondary interests at the cost of primary interest. Thirdly, there is a need to further explore the unconscious and conscious cognitive consequences of the conflict of interests. Fourthly, most of the research has focused on independence in appearance and not on that in fact. Fifth, there is a significant lack of research examining the implications of moral intuition for decision-making in the face of a conflict of interests. These five gaps converge into one main gap, i.e. a lack of understanding about how a conflict of interests operates at the level of an individual accounting professional.

The need to address the identified gap is supported by some researchers (Ayal and Gino 2012; Cain et al. 2005; Guiral et al. 2010; Moore et al. 2010). With reference to the gap in the literature, Tenbrunsel (2005) suggests that understanding the operation of conflict of interests is about recognising the cognitive obstacles (unconscious and conscious) to compliant decision-making, and then finding out how to overcome these barriers. Similarly, Moore et al. (2010) call for examining the interaction of conflict of interests with professionals' decision-making as a way to understand how such conflicts operate at the level of an individual professional.

Accordingly, in order to fill the identified gap, future research on managing conflict of interests in 
professional accounting firms can potentially explore the relationship between conflict of interests and the professionals' decision-making behaviour, the role of professionals' unconscious and conscious cognitive processes towards their decision-making behaviour, and perceptual biases due to conflict of interests. It is expected that research in these areas will help to;

- testify the threatening impact of different categories of conflict of interests on the accounting professionals' adoption of compliant behaviour,

- understand the role of accounting professionals' unconscious and conscious cognitive processes towards their decision-making behaviour in the events of conflict of interests,

- foster research on the implications of moral intuition for the professionals' judgement and decision-making behaviour, and

- understand the process through which the unintentional and/or intentional perceptual bias might increase the likelihood of deviant decision-making behaviour.

Since the proposed research areas are relevant to accounting professionals' state of mind, the insights obtained by addressing these concerns might be combined to strengthen their independence in fact and, resultantly, to facilitate the process of managing conflict of interests.

\section{Conclusions}

This paper summarised the extant research related to managing conflict of interests in professional accounting firms. The conflict of interests in professional accounting firms has been viewed through the lens of behavioural risk management which provides a new horizon for addressing the longstanding problem of accounting professionals' deviant behaviour due to conflict of interests. The synthesis of relevant research highlighted that the primary focus of existing measures and 
regulations on making the accounting professionals appear independent to the public (i.e. independence in appearance) is one of the reasons for the prevalence of the professionals' deviant behaviour. The existing measures and regulations need to be strengthened for dealing with the accounting professionals' actual objectivity and state of mind, i.e. their independence in fact. The key message is that, for effective management of conflict of interests, the behavioural interventions to strengthen the professionals' independence in fact should be informed by their unconscious (automatic) as well as the conscious (controlled) cognitive processes.

This research synthesis has the potential to guide future researchers for addressing conflict of interests as a topic deserving of its own focus. The identified gap(s) in the literature and the subsequent proposed research areas can guide future research seeking to understand the operation of conflict of interests at the level of an individual accounting professional. On a practical level, the professional accounting firms and other relevant professions, accounting professionals and the regulators can use this synthesised literature for making better decisions and improving their policies towards managing the risk of conflict of interests. This paper holds further significance because it views the conflict of interests, exclusively, through the lens of behavioural risk management. The framework adopted to review, interpret and analyse the existing literature is unique to this study. However, the classification of extant literature across the establishment of context, assessment, treatment, control and monitoring of conflict of interests should be considered as based on the researcher's discretion and having an element of subjectivity.

\section{Notes}

1. AICPA - American Institute of Certified Public Accountants; NASBA - National Association of State Boards of Accountancy; AAT - Association of Accounting Technicians; ACCA Association of Chartered Certified Accountants; ICAEW - Institute of Chartered Accountants in 
England and Wales; CIMA - Certified Institute of Management Accountants ; CIPFA - Chartered Institute of Public Finance and Accountancy ; ICAS - Institute of Chartered Accountants of Scotland (ICAS) ; CAI - Chartered Accountants Ireland.

\section{Compliance with Ethical Standards}

\section{Disclosure of Potential Conflict of Interests}

Conflict of Interest: I declare that I have no conflict of interest.

\section{Research Involving Human Participants and/or Animals}

This study does not involve human participants.

\section{Informed Consent}

This study does not involve human participants.

\section{References}

Adams, J., Tashchian, A. and Shore, T. (2001). Codes of Ethics as Signals for Ethical Behavior. Faculty Publications [online]. Available at: http://digitalcommons.kennesaw.edu/facpubs/1770.

Agnew, H. (2015). Professional Services: Accounting for Change [online]. Available at: https://next.ft.com/content/938ed6c6-36e6-11e5-bdbb-35e55cbae175. 
Ahmad, M. (2015). The impact of ex-auditors' employment with audit clients on perceptions of auditor independence in Malaysia. Procedia - Social and Behavioral Sciences, 172, 479-486.

Amali, J.W. (2010). Motivated to be Unethical. International Journal of Interdisciplinary Social Sciences, 5(3), 55.

Anderson-Gough, F., Grey, C. and Robson, K. (2001). Tests of time: organizational time-reckoning and the making of accountants in two multi-national accounting firms. Accounting, Organizations and Society, 26(2), 99-122.

Arel, B., Brody, R. and Pany, K. (2006). Findings on the Effects of Audit Firm Rotation on the Audit Process under Varying Strengths of Corporate Governance. Advances in Accounting, 22, 1-27.

Ashkanasy, N.M., Windsor, C.A. and Trevino, L.K. (2006). Bad Apples in Bad Barrels Revisited: Cognitive Moral Development, Just World Beliefs, Rewards and Ethical Decision Making. Business Ethics Quarterly, 16(1), 449-473.

Ayal, S. and Gino, F. (2012). Honest rationales for dishonest behavior. In: M. Mikulincer and P.R. Shaver, eds., The social psychology of morality: Exploring the causes of good and evil, Herzliya series on personality and social psychology. Washington, DC, US: American Psychological Association, pp.149-166.

Ayers, S. and Kaplan, S.E. (2003) 'Review Partners' Reactions to Contact Partner Risk Judgments of Prospective Clients'. Auditing: A Journal of Practice \& Theory, 22 (1), 29.

Bae, G.S., Kallapur, S. and Rho, J.H. (2013). Departing and Incoming Auditor Incentives and AuditorClient Misalignment under Mandatory Auditor Rotation: Evidence from Korea. [SSRN Scholarly 
Paper] Rochester, NY: Social Science Research Network. Available at: http://papers.ssrn.com/abstract=2281127.

Bangun, Y.K. and Asri, M. (2017) ‘Auditor Ethical Decision Making’. Scientific Research Journal, V (VI), 27-45.

Banker, R.D., Chang, H. and Kao, Y. (2002). Impact of Information Technology on Public Accounting Firm Productivity. Journal of Information Systems, 16(2), 209-222.

Bargh, J.A., Chaiken, S., Raymond, P. and Hymes, C. (1996). The Automatic Evaluation Effect: Unconditional Automatic Attitude Activation with a Pronunciation Task. Journal of Experimental Social Psychology, 32(1), 104-128.

Bargh, J.A. and Chartr, T.L. (1999). The unbearable automaticity of being. American Psychologist, 462479.

Bay, D. (2002). A critical evaluation of the use of the dit in accounting ethics research. Critical Perspectives on Accounting, 13(2), 159-177.

Bazerman, M.H., Loewenstein, G. and Moore, D.A. (2002). Why Good Accountants Do Bad Audits. Harvard Business Review, 11(1), 72-98.

Bazerman, M.H. and Gino, F. (2012). Behavioral Ethics: Toward a Deeper Understanding of Moral Judgement and Dishonesty. Annual Review of Law and Social Science, 8, 85-104.

Beasley, M., Carcello, J. and Hermanson, D. (2000). Preventing Fraudulent Financial Reporting. CPA Journal, 70(12), 14-21. 
Beasley, M.S., Carcello, J.V., Hermanson, D.R. and Lapides, P.D. (2000). Fraudulent Financial Reporting: Consideration of Industry Traits and Corporate Governance Mechanisms. Accounting Horizons, 14(4), 441-454.

Beattie, V. and Fearnley, S. (2002). Auditor Independence and Non-Audit Services: A Literature Review [online]. London, UK: Institute of Chartered Accountants in England \& Wales. Available at: http://eprints.gla.ac.uk/33531/.

Beattie, V., Fearnley, S. and Brandt, R. (2005). Auditor Independence and Audit Risk: A Reconceptualisation. Journal of International Accounting Research, 4(1), 39-71.

Bedard, J.C., Jackson, C., Ettredge, M.L. and Johnstone, K. (2003). The effect of training on auditors' acceptance of an electronic work system. International Journal of Accounting Information Systems, 4, 227-250.

Bedard, J., Ettredge, M., Jackson, C. and Johnstone, K. (2006). Knowledge, Experience and WorkAround Behaviors: Electronic Media in the Professional Audit Environment. [SSRN Scholarly Paper] Rochester, NY: Social Science Research Network. Available at: https://papers.ssrn.com/abstract=934200.

Bedard, J.C., Deis, D.R., Curtis, M.B. and Jenkins, J.G. (2008). Risk Monitoring and Control in Audit Firms: A Research Synthesis. Auditing: A Journal of Practice \& Theory, 27(1), 187-218.

Bobek, D.D. and Radtke, R.R. (2007). An Experiential Investigation of Tax Professionals' Ethical Environments. The Journal of the American Taxation Association, 29(2), 63-84. 
Bobek, D.D., Hageman, A.M., and Radtke, R.R. (2015). The Effects of Professional Role, Decision Context, and Gender on the Ethical Decision Making of Public Accounting Professionals. Behavioral Research in Accounting. 27 (1), 55-78.

Booth, P. and Schulz, A.K.-D. (2004). The impact of an ethical environment on managers' project evaluation judgements under agency problem conditions. Accounting, Organizations and Society, 29(5-6), 473-488.

Boyd, C. (2004). The Structural Origins of Conflicts of Interest in the Accounting Profession. Business Ethics Quarterly, 14(3), 377-398.

Cain, D.M., Loewenstein, G. and Moore, D.A. (2005). Coming Clean but Playing Dirtier: The Shortcomings of Disclosure as a Solution to Conflicts of Interest. In: D.A. Moore, D.M. Cain, G. Lowenstein and M.H. Bazerman, eds., Conflicts of Interest: Challenges and Solutions in Business, Law, Medicine and Public Policy. Cambridge University Press, p.104.

Caldarelli, A., Fiondella, C., Maffei, M., Spanò, R. and Zagaria, C. (2012). Ethics in Risk Management Practices: Insights from the Italian Mutual Credit Co-operative Banks. [online] Available at: http://library2.smu.ca:80/xmlui/handle/01/24727.

Casebeer, W.D. and Churchland, P.S. (2003). The Neural Mechanisms of Moral Cognition: A MultipleAspect Approach to Moral Judgement and Decision-Making. Biology and Philosophy, 18(1), 169194.

Chiu, R.K. (2003). Ethical Judgement and Whistleblowing Intention: Examining the Moderating Role of Locus of Control. Journal of Business Ethics, 43(1-2), 65-74. 
Chugh, Banaji, M.R. and Bazerman, M.H. (2005). Conflicts of interest: Problems and solutions from law, medicine and organizational settings. London: Cambridge University Press.

Citron, D.B. (2003). The UK's framework approach to auditor independence and the commercialization of the accounting profession. Accounting, Auditing \& Accountability Journal, 16(2), 244-274.

Clements, C.E., Neill, J.D. and Stovall, O.S. (2012). Inherent Conflicts of Interest in the Accounting Profession. Journal of Applied Business Research, 28(2), 269-276.

Cotterill, R. (2000). Enchanted Looms: Conscious Networks in Brains and Computers. New Ed edition. Cambridge, UK; New York, NY, USA: Cambridge University Press.

Cowton, C.J. (2009). Accounting and the Ethics Challenge: Remembering the Professional Body. Accounting and Business Research, 39 (3), 177-189.

Craswell, A., Stokes, D.J. and Laughton, J. (2002). Auditor independence and fee dependence. Journal of Accounting and Economics, 33(2), 253-275.

Crump, R. (2015). FRC hits KPMG with $£ 390,000$ in fines over ethical breaches. Accountancy Age [online]. Available at: https://www.accountancyage.com/aa/news/2393618/frc-hits-kpmg-withgbp390-000-in-fines-over-ethical-breaches.

Curtis, M.B. (2006). Whistleblower Mechanisms: A Study of the Perceptions of Users and Responders. The Institute of Internal Auditors.

Damasio, A.R. (1994). Descartes' Error: Emotion, Rationality and the Human Brain. New York: Putnam 352. 
Damasio, A.R. (2003). Looking for Spinoza: Joy, Sorrow, and the Feeling Brain. First edition. Orlando Toronto London: Harvest

Damasio, A.R. (2006). Descartes' error: emotion, reason and the human brain. London: Vintage.

Daugherty, B.E., Dickins, D., Hatfield, R.C. and Higgs, J.L. (2012). An Examination of Partner Perceptions of Partner Rotation: Direct and Indirect Consequences to Audit Quality. Auditing: A Journal of Practice \& Theory, 31(1), 97-114.

Davis, S., DeZoort, F.T. and Kopp, L.S. (2006). The Effect of Obedience Pressure and Perceived Responsibility on Management Accountants' Creation of Budgetary Slack. Behavioral Research in Accounting, 18(1), 19-35.

Defond, M.L. and Francis, J.R. (2005). Audit Research after Sarbanes-Oxley. Auditing: A Journal of Practice \& Theory, 24, 5-30.

Deis, D.R.J. and Giroux, G.A. (1992). Determinants of Audit Quality in the Public Sector. The Accounting Review, 67(3), 462-479.

Deis, D. and Rose, A.M. (2011). A Comparative Analysis of Audit Service Supply Using Desk and Working Paper Reviews. Journal of Business \& Economics Research, 2.

Dopuch, N., King, R.R. and Schwartz, R. (2001). An Experimental Investigation of Retention and Rotation Requirements. Journal of Accounting Research, 39(1), 93-117.

Dopuch, N., King, R.R., Schwartz, R. (2003). Independence in Appearance and in Fact: An Experimental Investigation. Contemporary Accounting Research, 20(1), 79-119. 
Douglas, P., Davidson, R. and Schwartz, B. (2001). The Effect of Organizational Culture and Ethical Orientation on Accountants' Ethical Judgments. Journal of Business Ethics, 34(2), 101-121.

Dowling, C. (2009). Appropriate Audit Support System Use: The Influence of Auditor, Audit Team and Firm Factors. [SSRN Scholarly Paper] Rochester, NY: Social Science Research Network. Available at: http://papers.ssrn.com/abstract=1317140.

Duska, R., Duska, B.S., and Ragatz, J. (2011) 'Accounting Codes of Conduct'. in Accounting Ethics $\begin{array}{llll}\text { [online] Wiley-Blackwell, } & \text { 77-92. } & \text { available }\end{array}$ http://onlinelibrary.wiley.com/doi/10.1002/9781444395907.ch5/summary.

Endenich, C. and Trapp, R. (2018). Ethical Implications of Management Accounting and Control: A Systematic Review of the Contributions from the Journal of Business Ethics. Journal of Business Ethics [online] available from https://doi.org/10.1007/s10551-018-4034-8.

Espinosa-Pike, M. and Barrainkua, I. (2016). An exploratory study of the pressures and ethical dilemmas in the audit conflict. Revista de Contabilidad, 19(1), 10-20.

Fatemi, D., Hasseldine, J., and Hite, P. (2018). The Influence of Ethical Codes of Conduct on Professionalism in Tax Practice. Journal of Business Ethics [online] available from https://doi.org/10.1007/s10551-018-4081-1.

Favere-Marchesi, M. and Emby, C.E.N. (2005). The Impact of Continuity on Concurring Partner Reviews: An Exploratory Study. Accounting Horizons, 19(1), 1-10.

Fearnley, Brandt, R. and Beattie (2002). Financial regulation of public limited companies in the UK: A way forward post-Enron. Journal of Financial Regulation and Compliance, 10(3), 254-265. 
Fearnley, S., Hines, T., Mcbride, K. and Brandt, R. (2002). The Impact of the Financial Reporting Review Panel on Aspects of the Independence of Auditors and Their Attitudes to Compliance in the UK. The British Accounting Review, 34(2), 109-139.

Financial Reporting Council (2016). Audit Quality Inspections Annual Report. [Inspections] Financial Reporting Council. Available at: https://www.frc.org.uk/Our-Work/Conduct/Audit-QualityReview/Audit-Quality-Review-annual-reports.aspx.

Flanagan, J., Clarke, K. (2007). Beyond a Code of Professional Ethics: A Holistic Model of Ethical Decision-Making for Accountants. Abacus, 43, 488-518.

Florio, C.V. di. (2012). Conflicts of Interest and Risk Governance. [online] US Securities and Exchange Commission. Available at: https://www.sec.gov/News/Speech/Detail/Speech/1365171491600.

Frankel, R.M., Johnson, M.F. and Nelson, K.K. (2002). The Relation Between Auditors' Fees for NonAudit Services and Earnings Management. [SSRN Scholarly Paper] Rochester, NY: Social Science Research Network. Available at: http://papers.ssrn.com/abstract=296557.

Geiger, M.A. and Raghunandan, K. (2002). Auditor Tenure and Audit Reporting Failures. [SSRN Scholarly Paper] Rochester, NY: Social Science Research Network. Available at: http://papers.ssrn.com/abstract=276695.

Geiger, M.A., North, D.S. and O'Connell, B.T. (2005). The Auditor-to-Client Revolving Door and Earnings Management. Journal of Accounting, Auditing \& Finance, 20(1), 1-26.

Gonzalez, C., Dana, J., Koshino, H. and Just, M. (2005). The framing effect and risky decisions: Examining cognitive functions with fMRI. Journal of Economic Psychology, 26(1), 1-20. 
Goto, S. (2004). A behavioral risk management system. [online] Available at: http://academiccommons.columbia.edu/catalog/ac:119284.

Green, D.P., Ha, S.E. and Bullock, J.G. (2010). Enough Already About 'Black Box' Experiments: Studying Mediation is More Difficult than Most Scholars Suppose. Annals of the American Academy of Political and Social Science, 628, 200-208.

Green, J. and Zimiles, E. (2013). Conflicts of Interest. Investigations Quarterly, 1(14), 8-12.

Greene, J.D., Sommerville, R.B., Nystrom, L.E., Darley, J.M. and Cohen, J.D. (2001). An fMRI investigation of emotional engagement in moral judgement. Science (New York, N.Y.), 293(5537), pp.2105-2108.

Greene, J.D., Nystrom, L.E., Engell, A.D., Darley, J.M. and Cohen, J.D. (2004). The neural bases of cognitive conflict and control in moral judgement. Neuron, 44(2), 389-400.

Guiral, A., Rodgers, W., Ruiz, E. and Gonzalo, J.A. (2010). Ethical Dilemmas in Auditing: Dishonesty or Unintentional Bias? Journal of Business Ethics, 91(1), 151-166.

Haidt, J. (2001). The Emotional Dog and Its Rational Tail: A Social Intuitionist Approach to Moral Judgment. Psychological Review, 108 (4), 814-834

Hatfield, R.C., Jackson, S.B. and Vandervelde, S.D. (2011). The Effects of Prior Auditor Involvement and Client Pressure on Proposed Audit Adjustments. Behavioral Research in Accounting, 23(2), 117-130. 
Healy, P.M. and Palepu, K.G. (2001). Information asymmetry, corporate disclosure and the capital markets: A review of the empirical disclosure literature. Journal of Accounting and Economics, 31(1-3), 405-440.

Hermann, H., Trachsel, M., and Biller-Andorno, N. (2017). Accounting for Intuition in Decision-Making Capacity: Rethinking the Reasoning Standard? Philosophy, Psychiatry, \& Psychology 24, 313324.

IESBA (2015). 2015 Handbook of the Code of Ethics for Professional Accountants [online] International Federation of Accountants. Available at: http://www.ethicsboard.org/.

IESBA (2018). 2018 Handbook of the International Code of Ethics for Professional Accountants [online] Available at: https://www.ethicsboard.org/iesba-code.

ISO (2009). ISO 31000:2009-Risk Management Principles and Guidelines. [online] ISO 31000:2009. Available at: http://www.iso.org/iso/catalogue_detail?csnumber=43170.

Iyer, V.M. and Rama, D.V. (2004). Clients' Expectations on Audit Judgements: A Note. Behavioral Research in Accounting, 16(1), 63-74.

Jepma, M. and López-Solà, M. (2014). Anxiety and framing effects on decision making: insights from neuroimaging. The Journal of Neuroscience: The Official Journal of the Society for Neuroscience, 34(10), 3455-3456.

Johnson, E., Khurana, I.K. and Reynolds, J.K. (2002). Audit-Firm Tenure and the Quality of Financial Reports. Contemporary Accounting Research, 19(4), 637-660.

Johnson, R.N. and Hansen, G.R. (2011). Audit Fees and Engagement Profitability. The CPA Journal. 
Jones, J., Massey, D.W. and Thorne, L. (2003). Auditor's Ethical Reasoning: Insights from Past Research and Implications for the Future. Journal of Accounting Literature, 22, 45-103.

Juhari, R.J., Mohd-Sanusi, Z., Rahman, R.A. and Omar, N.B. (2013). Auditors' Independence, Experience and Ethical Judgements: The Case of Malaysia. Journal of Business and Policy Research, 8(1), 100-119.

Ishaque, M. (2019). Cognitive approach to understand the impact of conflict of interests on accounting $\begin{array}{lll}\text { professionals' } & \text { decision-making }\end{array}$ Forum, DOI: 10.1080/01559982.2019.1583303.

Kadous, K., Kennedy, S.J. and Peecher, M.E. (2003). The Effect of Quality Assessment and Directional Goal Commitment on Auditor's Acceptance of Client-Preferred Accounting Methods. The Accounting Review, 78(3), 759-778.

Kahneman, D. and Frederick, S. (2002). Representativeness Revisited: Attribute Substitution in Intuitive Judgement. In: Heuristics and Biases. [online] Cambridge University Press. Available at: http://dx.doi.org/10.1017/CBO9780511808098.004.

Kaplan, S.E. and Whitecotton, S.M. (2001). An Examination of Auditors' Reporting Intentions When Another Auditor Is Offered Client Employment. Auditing: A Journal of Practice \& Theory, 20(1), 45-63.

Kinney, W.R., Palmrose, Z.-V. and Scholz, S. (2004). Auditor Independence, Non-Audit Services and Restatements: Was the U.S. Government Right? Journal of Accounting Research, 42(3), 561-588. 
Koh, H.C. and Mahathevan, P. (1993). The Effects of Client Employment on Auditor Independence. The British Accounting Review, 25(3), 227-242.

Kung, F.-H. and Huang, C.L. (2013) Auditors' Moral Philosophies and Ethical Beliefs. Management Decision [online]. Available at: /insight/content/doi/10.1108/00251741311309616/full/html.

Lakoff, G. and Johnson, M. (1999). Philosophy in the Flesh: The Embodied Mind \& Its Challenge to Western Thought. New York, NY: Basic Books.

Latan, H., Chiappetta Jabbour, C.J., and Lopes de Sousa Jabbour, A.B. (2019). Ethical Awareness, Ethical Judgment and Whistleblowing: A Moderated Mediation Analysis. Journal of Business Ethics. 155 (1), 289-304

LeDoux, J.E. (1999). The emotional brain: the mysterious underpinnings of emotional life. London: Phoenix.

Lennox, C. (2003). Opinion Shopping and the Role of Audit Committees When Audit Firms Are Dismissed: The US Experience. Edinburgh: Institute of Chartered Accountants of Scotland.

Lo, B. and Field, M.J. eds. (2009). Conflict of Interest in Medical Research, Education and Practice. The National Academies Collection: Reports funded by National Institutes of Health. [online] Washington (DC): National Academies Press (US). Available at: http://www.ncbi.nlm.nih.gov/books/NBK22942/.

Mayhew, B.W. and Pike, J. (2004). Does Investor Selection of Auditors Enhance Auditor Independence? [SSRN Scholarly Paper] Rochester, NY: Social Science Research Network. Available at: http://papers.ssrn.com/abstract=557181. 
McMillan, K.P. (2004). Trust and the virtues: a solution to the accounting scandals? Critical Perspectives on Accounting, 15(6-7), 943-953.

McPhail, K. (2006). Ethics and the Individual Professional Accountant: A Literature Review. [online] The Institute of Chartered Accountants of Scotland. Available at: http://icas.org.uk/mcphail/.

Menon, K. and Williams, D.D. (2004). Former Audit Partners and Abnormal Accruals. The Accounting Review, 79(4), 1095-1118.

Moll, J., de Oliveira-Souza, R., Moll, F.T., Ignácio, F.A., Bramati, I.E. Caparelli-Dáquer, E.M. and Eslinger, P.J. (2005). The moral affiliations of disgust: a functional MRI study. Cognitive and behavioral neurology: official journal of the Society for Behavioral and Cognitive Neurology, $18(1), 68-78$.

Moore, D.A., Loewenstein, G., Tanlu, L. and Bazerman, M.H. (2003). Auditor independence, conflict of interest and the unconscious intrusion of bias. Working paper / Division of Research, Harvard Business School; 03-116. Boston, Mass.

Moore, D.A. and Loewenstein, G. (2004). Self-Interest, Automaticity and the Psychology of Conflict of Interest. Social Justice Research, 17(2), pp.189-202.

Moore, D.A., Cain, D.M., Loewenstein, G. and Bazerman, M.H. (2005). Conflicts of Interest: Challenges and Solutions in Business, Law, Medicine and Public Policy. Cambridge University Press. 
Moore, D.A., Tetlock, P.E., Tanlu, L. and Bazerman, M.H. (2006). Conflicts of Interest and The Case of Auditor Independence: Moral Seduction and Strategic Issue Cycling. Academy of Management Review, 31(1), 10-29.

Moore, D.A., Tanlu, L. and Bazerman, M. (2010). Conflict of Interest and the Intrusion of Bias. [online] Available at: http://www.hbs.edu/faculty/Pages/item.aspx?num=37624.

Near, J.P., Rehg, M., Scotter Jr, V. and Miceli, M.P. (2004). Developing a Model of the Whistle-Blowing Process: How Does Type of Wrongdoing Affect the Process. Business Ethics Quarterly, 14, 219242.

Nelson, M.W. (2004). A Review of Experimental and Archival Conflicts-of-Interest Research in Auditing. [SSRN Scholarly Paper] Rochester, NY: Social Science Research Network. Available at: http://papers.ssrn.com/abstract=511383.

O’Connor, S.M. (2006). Strengthening Auditor Independence by Reducing the Need for It: Reestablishing Audits as Control and Premium Signaling Mechanisms. [SSRN Scholarly Paper] Rochester, NY: Social Science Research Network. Available at: http://papers.ssrn.com/abstract $=911881$.

Otley, D.T. and Pierce, B.J. (1996). Auditor time budget pressure: consequences and antecedents. Accounting, Auditing \& Accountability Journal, 9(1), 31-58.

Panksepp, J. (1998). Affective neuroscience: the foundations of human and animal emotions. New York: Oxford University Press. 
Panksepp, J. (2009). Brain Emotional Systems and Qualities of Mental Life: From Animal Models of Affect to Implications for Psychotherapeutics. In The Healing Power of Emotion: Affective Neuroscience, Development \& Clinical Practice. New York, NY, US: W. W. Norton \& Company, $1-26$.

Pierce, B. and Sweeney, B. (2004). Cost-quality conflict in audit firms: an empirical investigation. European Accounting Review, 13(3), 415-441.

Pierce, A. (2007). Ethics and the Professional Accounting Firm: A Literature Review. The Institute of Chartered Accountants of Scotland.

Preston, A.M., Cooper, D.J., Scarbrough, D.P. and Chilton, R.C. (1995). Changes in the code of ethics of the U.S. accounting profession, 1917 and 1988: The continual quest for legitimation. Accounting, Organizations and Society, 20(6), 507-546.

Reinstein, A. and McMillan, J.J. (2004). The Enron debacle: more than a perfect storm. Critical Perspectives on Accounting, 15(6-7), 955-970.

Reiter, S.A. (1996). The Kohlberg-Gilligan Controversy: Lessons for Accounting Ethics Education. Critical Perspectives on Accounting, 7(1), 33-54.

Rodgers, W. (2006). Process Thinking: Six Pathways to Successful Decision Making. iUniverse.

Rodgers, W. (2009). Ethical Beginnings: Preferences, Rules and Principles Influencing Decision Making. iUniverse.

Rodgers, W. and Gago, S. (2001). Cultural and Ethical Effects on Managerial Decisions: Examined in a Throughput Model. Journal of Business Ethics, 31(4), 355-367. 
Rodgers, W. and Gago, S. (2006). Biblical Scriptures Underlying Six Ethical Models Influencing Organizational Practices. Journal of Business Ethics, 64(2), 125-136.

Ronen, J. (2010). Corporate Audits and How to Fix Them. Journal of Economic Perspectives, 24(2), 189-210.

Ruddock, C.M.S., Taylor, S.J. and Taylor, S.L. (2004). Non-Audit Services and Earnings Conservatism: Is Auditor Independence Impaired? [SSRN Scholarly Paper] Rochester, NY: Social Science Research Network. Available at: http://papers.ssrn.com/abstract=303343.

Sánchez-Medina, A.J., Blázquez-Santana, F., and Alonso, J.B. (2019). Do Auditors Reflect the True Image of the Company Contrary to the Clients' Interests? An Artificial Intelligence Approach. Journal of Business Ethics. 155 (2), 529-545.

Schminke, M., Arnaud, A. and Kuenzi, M. (2007). The Power of Ethical Work Climates. Organizational Dynamics, 36(2), 171-186.

Schneider, W. and Shiffrin, R.M. (1977). Controlled and automatic human information processing: I. Detection, search and attention. Psychological Review, 84(1), 1-66.

Shafer, W.E., Morris, R.E. and Ketchand, A.A. (2001). Effects of personal values on auditors' ethical decisions. Accounting, Auditing \& Accountability Journal, 14(3), 254-277.

Sharma, D.S. and Sidhu, J. (2001). Professionalism vs Commercialism: The Association Between NonAudit Services (NAS) and Audit Independence. Journal of Business Finance \& Accounting, 28(56), 563-594. 
Sikka, P. (2004). Some questions about the governance of auditing firms. International Journal of Disclosure and Governance, 1(2), 186-200.

Skaife, H.A., LaFond, R. and Mayhew, B.W. (2003). Do Non-Audit Services Compromise Auditor Independence? Further Evidence. [SSRN Scholarly Paper] Rochester, NY: Social Science Research Network. Available at: http://papers.ssrn.com/abstract=305720.

Stead, W.E., Worrell, D.L., Spalding, J.B. and Stead, J.G. (1987). Unethical Decision: Socially Learned Behaviours. Journal of Social Behaviour and Personality, 2(1), 105-115.

Stumpf, S.A., P. Doh, J. and D. Clark, K. (2002). Professional Services Firms in Transition: Challenges and Opportunities for Improving Performance. Organizational Dynamics, 31(3), 259-279.

Tavakoli, A.A., Keenan, J.P. and Cranjak-Karanovic, B. (2003). Culture and Whistleblowing: An Empirical Study of Croatian and United States Managers Utilizing Hofstede's Cultural Dimensions. Journal of Business Ethics, 43(1-2), 49-64.

Tepalagul, N. and Lin, L. (2014). Auditor Independence and Audit Quality: A Literature Review. Journal of Accounting, Auditing \& Finance, 30(1), 101-121.

Tenbrunsel, A.E. (2005). Commentary: Bounded Ethicality and Conflicts of Interest. In: Conflicts of Interest: Challenges and Solutions in Business, Law, Medicine and Public Policy. Cambridge University Press.

Thagard, P. (2007). The Moral Psychology of Conflicts of Interest: Insights from Affective Neuroscience. Journal of Applied Philosophy, 24(4), 367-8211. 
Treviño, L.K., Brown, M. and Hartman, L.P. (2003). A Qualitative Investigation of Perceived Executive Ethical Leadership: Perceptions from Inside and Outside the Executive Suite. Human Relations, $56(1), 5-37$.

Trotman, K.T., Wright, A.M. and Wright, S. (2005). Auditor Negotiations: An Examination of the Efficacy of Intervention Methods. The Accounting Review, 80(1), 349-367.

Tucker, R. and Matsumura, E.M. (2002). Second Partner Review: An Experimental Investigation. [SSRN Scholarly Paper] Rochester, NY: Social Science Research Network. Available at: https://papers.ssrn.com/abstract=313919.

Wagar, B.M. and Thagard, P. (2004). Spiking Phineas Gage: a neurocomputational theory of cognitiveaffective integration in decision making. Psychological review, 111(1), 67-79.

Weaver, G.R. and Treviño, L.K. (2001). The role of human resources in ethics/compliance management: a fairness perspective. Human Resource Management Review, 11(1-2), 113-134.

Weaver, G.R., Reynolds, S.J., and Brown, M.E. (2014). Moral Intuition: Connecting Current Knowledge to Future Organizational Research and Practice. Journal of Management 40 (1), 100-129.

Williford, K. and Small, D. (2013). Establishing an Effective Compliance Program: An Overview to Protecting Your Organization. [online] Association of Corporate Counsel. Available at: http://www.acc.com/legalresources/quickcounsel/eaecp.cfm.

Withers, I. (2018). Grant Thornton Fined $£ 3 m$ over Conflicts of Interest on Audits. The Telegraph [online]. Available at: https://www.telegraph.co.uk/business/2018/08/29/grant-thornton-fined3m-conflicts-interest-audits/. 
Woiceshyn, J. (2011). A Model for Ethical Decision Making in Business: Reasoning, Intuition, and Rational Moral Principles. Journal of Business Ethics. 104, 1-13

Wolford, G., Miller, M.B. and Gazzaniga, M. (2000). The Left Hemisphere's Role in Hypothesis Formation. The Journal of Neuroscience, 20(6), RC64.

Worrell, D.L., Stead, W.E., Stead, J.G. and Spalding, J.B. (1985). Unethical decisions: the impact of reinforcement contingencies and managerial philosophies. Psychological reports, 57(2), 355-365.

Wyatt, A.R. (2004). Accounting Professionalism-They Just Don't Get It! Accounting Horizons, 18(1), 45-53.

Young, J.J. (2005). Changing Our Questions: Reflections on the Corporate Scandals. Accounting and the Public Interest, 5(1), 1-13.

Zajonc, R.B. (1980). Feeling and thinking: Preferences need no inferences. American Psychologist, $35(2), 151-175$.

Zajonc, R.B. (1984). On the primacy of affect. American Psychologist, 39(2), 117-123.

Zajonc, R.B. and McIntosh, D.N. (1992). Emotions Research: Some Promising Questions and Some Questionable Promises. Psychological Science, 3(1), 70-74.

Zollo, L., Pellegrini, M.M., and Ciappei, C. (2017). What Sparks Ethical Decision Making? The Interplay Between Moral Intuition and Moral Reasoning: Lessons from the Scholastic Doctrine. Journal of Business Ethics, 145 (4), 681-700. 